\title{
Dynamic water vapour sorption properties of wood treated with glutaraldehyde
}

\author{
Yanjun Xie $\cdot$ Callum A. S. Hill $\cdot$ Zefang Xiao • \\ Carsten Mai $\cdot$ Holger Militz
}

Received: 24 August 2009/Published online: 27 February 2010

(C) Springer-Verlag 2010

\begin{abstract}
The dynamic water vapour sorption properties of Scots pine (Pinus sylvestris L.) wood samples were studied to investigate the modifying effects of glutaraldehyde. Pine sapwood was treated with solutions of glutaraldehyde and a catalyst (magnesium chloride) to obtain weight per cent gains of $0.5,8.6,15.5$, and $21.0 \%$, respectively. The sorption behaviour of untreated and treated wood was measured using a Dynamic Vapour Sorption apparatus. The results showed considerable reduction in equilibrium moisture content of wood and the corresponding equilibrium time at each target relative humidity $(\mathrm{RH})$ due to glutaraldehyde treatment. The moisture adsorption and desorption rates of modified and unmodified wood were generally faster in the low RH range (up to approximate 20\%) than in the high range. Modification primarily reduced the adsorption and desorption rates over the high $\mathrm{RH}$ range of $20-95 \%$. Glutaraldehyde modification resulted in a reduction in sorption hysteresis due to the loss of elasticity of cell walls.
\end{abstract}

\section{Introduction}

Wood is a hygroscopic polymer due to the presence of an abundance of $\mathrm{OH}$ groups associated with the cell wall polymers. When wood is utilized outdoors, it is susceptible to abiotic and biotic damages such as weathering and fungal decay, which are related to the variation of the wood moisture content. Wood is an anisotropic polymeric material, and the water vapour sorption behaviour is different

\footnotetext{
Y. Xie $(\bowtie) \cdot$ C. A. S. Hill

Centre for Timber Engineering, School of Engineering and the Built Environment,

Edinburgh Napier University, 10 Colinton Road, EH10 5DT Edinburgh, UK

e-mail: y.xie@napier.ac.uk

Wood Biology and Wood Products, Burckhardt-Institute,

Georg August University of Göttingen, Büsgenweg 4, D37077 Göttingen, Germany
} 
between earlywood and latewood cell walls or sapwood and heartwood (Neimsuwan et al. 2008), which will cause uneven swelling or shrinkage at different dimensions. Such moisture-related dimensional change can produce interior stresses in the wood thereby inducing checking and cracking (Hoadley 1980; Jakiela et al. 2008). Moisture also participates in and accelerates surface photodegradation of wood during outdoor exposure. Under suitable moisture conditions, moulds and decay fungi can grow on/in the wood causing the losses of aesthetics and mechanical strength. Consequently, controlling the wood moisture is an important approach to prolonging the service life of outdoor exposed wood.

Chemical modification is one of the strategies to change the moisture sorption properties of wood primarily through the covalent bonding of chemicals with the hydroxyl groups of cell wall polymers or by depositing sterically fixed compounds, mainly of high molecular weight, in the cell wall (Hill 2006). As a result, the hygroscopic hydroxyl groups of cell walls are partly blocked, and the nanopores (nanocapillaries) of cell walls are filled with the chemicals. Blocking of hydroxyl groups reduces the sorption sites to water, and deposition of chemicals in the cell walls reduces the space for moisture thereby simultaneously making the cell walls drier and more dimensionally stable.

To date, the acetylation of wood with anhydrides has been the most intensively studied chemical modification process. The anhydride can incorporate into cell walls and substitute the hydroxyl groups (Spalt 1958; Papadopoulos 2005; Hill 2006). A large decrease in equilibrium moisture content (EMC) has been reported due to wood acetylation treatment (Chang and Chang 2002; Epmeier et al. 2007). The decrease has been attributed to the reduced sorption sites due to the deactivation of hydroxyl groups but, more crucially, the deposition of chemicals in the nanopores (bulking) (Chang and Chang 2002; Papadopoulos and Hill 2003; Hill 2006, 2008).

An alternative approach is to crosslink the cell wall polymers. Glutaraldehyde (GA, pentane-1,5-dial) is a dialdehyde, which can in principle react with four hydroxyl groups of the cell wall polymers and may thus be used as a crosslinking agent to modify wood. An aldehyde can react with one hydroxyl group to form a hemiacetal and with a second to produce an acetal. Whilst the hemiacetal formed is susceptible to hydrolysis, the acetal bond is stable under both neutral and acidic conditions. The crosslinking reaction can be facilitated by heating the treated wood in the presence of catalysts (Yasuda and Minato 1994; Yasuda et al. 1994; Xiao et al. 2009). Treatments of Scots pine sapwood with glutaraldehyde and magnesium chloride as a catalyst were shown to cause a reduction in the EMC of up to $30 \%$. The anti-swelling efficiency (ASE) at water saturation was $70 \%$ when the wood was treated to a weight per cent gain (WPG) of approximately $20 \%$ (Xiao et al. 2009). Glutaraldehyde treatment reduced both the maximum swelling and shrinking, suggesting that both bulking and crosslinking occur within the wood cell walls (Xiao et al. 2010).

Determining the EMC of wood at a given relative humidity $(\mathrm{RH})$ is a means of evaluating the sorption properties of wood and the effectiveness of wood modification (Hill 2006). The gravimetric method is a suitable way to determine the EMC by conditioning the wood samples over different saturated salt solutions to attain a desired RH (Papadopoulos and Hill 2003; Hernández 2007). Recently, dynamic vapour sorption (DVS) has been used to investigate the sorption properties 
of different natural fibres (Hill et al. 2009a), cotton fabric (Leisen et al. 2002), and Sitka spruce wood (Hill et al. 2009b). This DVS technique yields highly reproducible data and is able to provide accurate isotherms over a wide $\mathrm{RH}$ range (Hill et al. 2009a) and the temperature can also be varied.

The main objective of this study is to establish the effect of glutaraldehyde modification on the dynamic vapour sorption properties of wood by using a Dynamic Vapour Sorption apparatus. The changes of environmentally RH and moisture content of wood were recorded, and then the equilibrium time and moisture increment and decrement of wood at each given relative humidity were analysed accordingly.

\section{Materials and methods}

\section{Wood and chemicals}

Wood blocks measuring $5 \mathrm{~mm}$ (longitudinally) $\times 20 \mathrm{~mm}$ (tangentially) $\times 20 \mathrm{~mm}$ (radially) were cut from the sapwood of Scots pine (Pinus sylvestris L.) boards. The modifying agent was a $50 \mathrm{wt} \%$ solution of glutaraldehyde (GA) supplied by BASF AG (Ludwigshafen, Germany). Magnesium chloride hexahydrate $\left(\mathrm{MgCl}_{2} \cdot 6 \mathrm{H}_{2} \mathrm{O}\right)$ was used as catalyst.

\section{Treatment of wood}

Ten wood blocks were impregnated in aqueous acetate buffer solutions $(0.1 \mathrm{M}$, $\mathrm{pH} 4.5)$ of $4,12,20$, and $30 \%$ glutaraldehyde and $12.5 \%$ magnesium chloride (relative to the weight of glutaraldehyde), respectively, under vacuum conditions (100 mbar, $30 \mathrm{~min})$ and pressure (10 bar, 1 h). After impregnation, excess treatment solution was blotted off the wood blocks with tissue paper, and the wood blocks were air dried for 1 week. Subsequently, the specimens were pre-cured at $80^{\circ} \mathrm{C}(6 \mathrm{~h})$ and then finally cured at $120^{\circ} \mathrm{C}(48 \mathrm{~h})$.

After conditioning $\left(20^{\circ} \mathrm{C}, 65 \% \mathrm{RH}\right)$ for $24 \mathrm{~h}$, all the untreated and treated specimens were leached with daily changed tap water for 1 week to remove the unreacted glutaraldehyde and magnesium chloride and subsequently oven dried and weighed. The treated and leached samples ultimately attained the weight per cent gains of $0.5,8.6,15.5$, and $20.9 \%$, respectively. Untreated wood blocks served as control specimens. The untreated and treated wood blocks were ground into wood flour and passed through a 20-mesh sieve.

\section{Determination of dynamic water vapour sorption}

Isotherm analysis of wood flour was studied using a Dynamic Vapour Sorption apparatus (DVS Intrinsic, Surface Measurement Systems Ltd, London, United Kingdom) as previously reported (Hill et al. 2009a). Wood flour prepared as above of ca. $20 \mathrm{mg}$ was placed on the sample holder, which is connected to a microbalance by a hanging wire and is located in a thermostatically controlled cabinet. The pre-set 
$\mathrm{RH}$ increased in steps in the following sequence $(0,5,10,15,20,30,40,50,60,70$, $80,85,90$, and $95 \% \mathrm{RH}$ ), before decreasing to $0 \% \mathrm{RH}$ in the reverse order. The sorption processes were run at a constant temperature of $25^{\circ} \mathrm{C}$ over the full $\mathrm{RH}$ range. The instrument maintained a constant target $\mathrm{RH}$ until the sample moisture content change per minute $(\mathrm{dm} / \mathrm{dt})$ was less than $0.002 \%$ per minute over a $10 \mathrm{~min}$ period. In practice, this does not mean that it reaches a true equilibrium, but previous studies have established that this allows for obtaining EMC values within $0.1 \%$ of the true equilibrium value (i.e., infinite time). The running time, target $\mathrm{RH}$, actual RH, sample mass were recorded throughout the isotherm run.

Calculation of moisture content

The equilibrium moisture content (EMC) of untreated and treated wood as measured by the Dynamic Vapour Sorption apparatus was calculated based on the mass of modified wood (referred to as MC) and on the mass of wood before modification (referred to as $\mathrm{MC}_{\mathrm{R}}$ ), respectively:

$$
\begin{aligned}
\mathrm{MC} & =\frac{m_{2}-m_{1}}{m_{1}} \times 100 \\
\mathrm{MC}_{\mathrm{R}} & =\frac{m_{2}-m_{1}}{m_{0}} \times 100
\end{aligned}
$$

where $\mathrm{MC}$ is the measured EMC of untreated and modified wood; $\mathrm{MC}_{\mathrm{R}}$ is the reduced EMC of modified wood based on the mass of wood before treatment; $m_{0}$ is the dry mass of wood before modification; $m_{1}$ is the dry mass of wood after modification; $m_{2}$ is the equilibrium mass of wood at a given RH. MC takes no account of the fact that the mass of the sample is increased due to modification. $\mathrm{MC}_{\mathrm{R}}$, however, reflects the effect of incorporation of chemicals on the sorption isotherms of wood cell walls. For the untreated wood, $\mathrm{MC}$ equals $\mathrm{MC}_{\mathrm{R}}$.

\section{Results and discussion}

Dynamic sorption behaviour of wood

The response of a wood sample to the change in the set RH produced an asymptotic curve approaching the equilibrium moisture content (EMC) after infinite time of exposure at a given RH (Fig. 1). Treatments with glutaraldehyde caused a reduction in measured moisture content $(\mathrm{MC})$ and reduced moisture content $\left(\mathrm{MC}_{\mathrm{R}}\right)$ during the sorption process and both apparently decreased as WPG of wood increased (Fig. 1b, $\mathrm{c}$, and $\mathrm{d}$ ). The $\mathrm{MC}_{\mathrm{R}}$ value was higher than $\mathrm{MC}$, and the differences were greater with the increase in WPG (Fig. 1) according to Eqs. 1 and 2 that the mass of drymodified wood $\left(m_{1}\right)$ is always higher than the mass of dry wood before treatment $\left(m_{0}\right)$ due to the incorporation of chemicals. Compared to the EMC $(21.6 \%$ at $\mathrm{RH}$ $95 \%$ ) of untreated sample (Fig. 1a), wood treated to WPGs of $0.5,8.6,20.9 \%$ obtained the reduced moisture content $\left(\mathrm{MC}_{\mathrm{R}}\right)$ of 20.4, 16.6, and 13.6\% (Fig. 1b, c, 

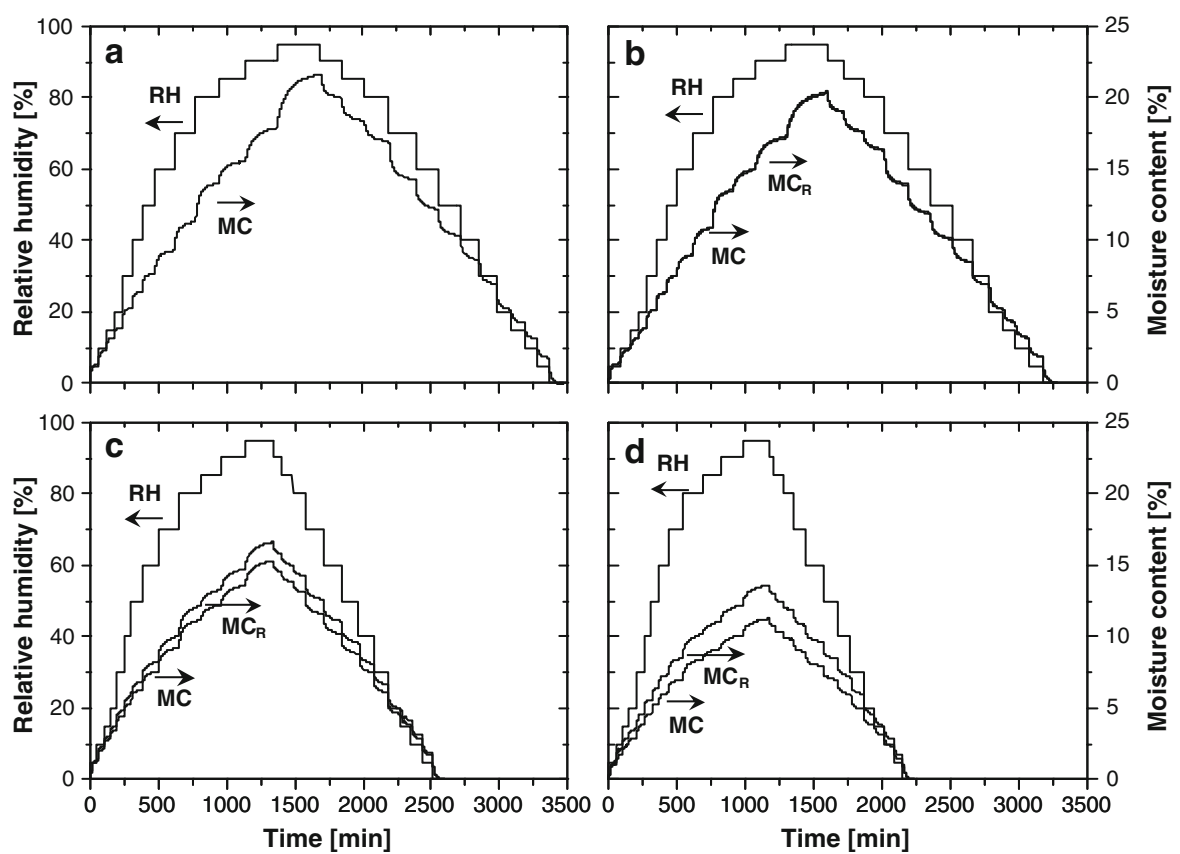

Fig. 1 Measured moisture content (MC) and reduced moisture content $\left(\mathrm{MC}_{\mathrm{R}}\right)$ of wood during the sorption run under stepwise target relative humidity (RH). a Untreated control, $\mathbf{b}$ treated to WPG of $0.5 \%$, c treated to WPG of $8.6 \%, \mathbf{d}$ treated to WPG of $20.9 \%$

and d), respectively. This shows that a considerable reduction in moisture adsorption occurs due to glutaraldehyde treatment.

Moisture adsorption and desorption rate of wood samples

The total running time taken throughout the sorption run was apparently reduced by glutaraldehyde treatment of the wood, and it reduced with increasing WPG (Fig. 1). However, it has to be considered that the running time is related not only to the material properties but also to the sample mass used for DVS measurement. Although the amount of measured sample was ca. $20 \mathrm{mg}$, it varied slightly from run to run. In order to compare the time needed for wood reaching an EMC at a given $\mathrm{RH}$ (referred to this time as equilibrium time), the data were normalized on the basis of sample mass used ( $\mathrm{min} \cdot \mathrm{mg}^{-1}$ ) as shown in Fig. $2 \mathrm{~b}$. In addition, the moisture increment in the adsorption isotherm and moisture decrement in the desorption isotherm at each given RH was also calculated and plotted (Fig. 2a).

The moisture increment of all samples decreased with the increase in RH with a step of $5 \%$ (Fig. 2a), but the equilibrium time was relatively short and remained almost invariable in the $\mathrm{RH}$ range of 5-20\% (Fig. 2b). This resulted in a decrease in moisture adsorption rate (Fig. 2c). In this low RH range, the isotherm process has been proposed to be dominated by a fast monolayer water adsorption on the sorption sites of wood hydroxyl groups (Skaar 1988). With the increase in RH from $20 \%$ up to $95 \%$, both the 

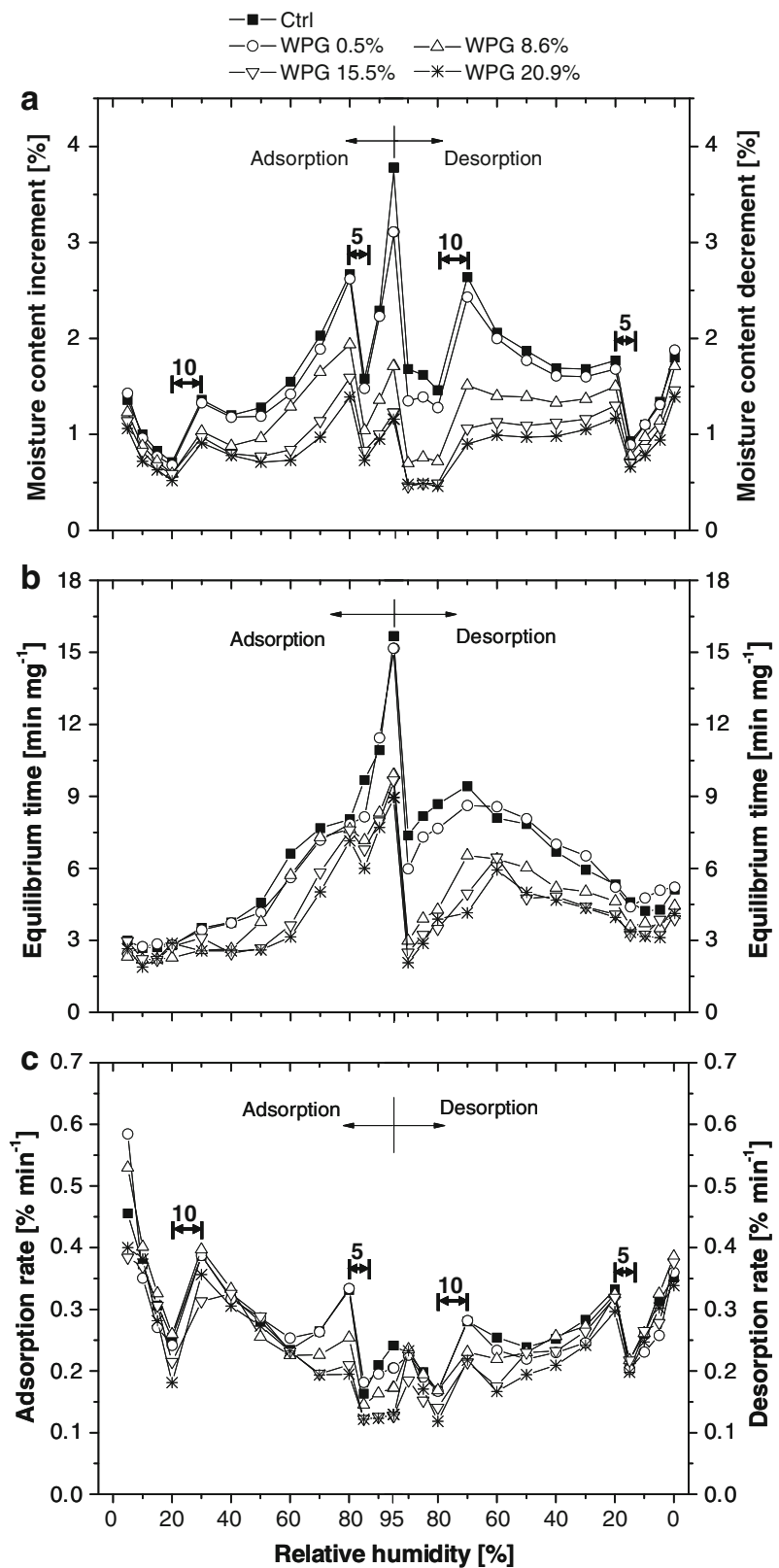

Fig. 2 Moisture content (MC) increment and decrement (a), equilibrium time (b), and moisture adsorption and desorption rate (c) of untreated and treated wood at each given RH level over the full RH range. The moisture adsorption and desorption rates were attained by dividing moisture content increment or decrement by equilibrium time. Left side of figures shows the adsorption isotherm over a RH range from 0 to $95 \%$, and right side displays the desorption isotherm over a $\mathrm{RH}$ range from 95 to $0 \%$. The bidirectional arrows with number show the changes of RH step 
moisture increment and equilibrium time at a given $\mathrm{RH}$ gradually increased (Fig. 2a, b), but the moisture adsorption rate generally decreased (Fig. 2c). The reduction in the moisture adsorption rate may be determined by the cell wall structure. With the increased moisture content, the viscoelastic cell walls swell to accommodate more water under the environmental water vapour pressure; however, unlike a gel, the cell wall cannot swell without limitation due to its complex structure. It has been shown that the sorption kinetics behaviour of smaller wood particles, such as used herein, fits a parallel exponential kinetics model and is not diffusion limited (Hill et al. 2009b). This implies that the ability of the cell wall to swell to accommodate water molecules is the rate-limiting step controlling the sorption process. The plasticization of cell wall macromolecules at higher RH values has been shown by NMR. The NMR study of the sorption isotherm of cotton fabric has revealed that with the increase in RH over $35 \%$ some portion of cellulose hydroxyl groups becomes mobile due to the fast exchange between the sorbed water and the cellulosic $-\mathrm{OH}$ groups and/or plasticization and thus mobilization of some segments of cellulose matrix (Topgaard and Södermann 2001; Leisen et al. 2002). However, the plasticized $-\mathrm{OH}$ groups are only $30 \%$ of total cellulosic-OH groups at the $85 \% \mathrm{RH}$ level because the other inaccessible-OH groups locate in the crystalline region of cellulose (Leisen et al. 2002). A plasticization effect of this type increases chain mobility and hence the swellability of the cell wall. Such a model is consistent with a reduction in sorption rate as RH increases. The capillary condensation also may occur in the higher $\mathrm{RH}$ range as the water vapour pressure increases with the increased $\mathrm{RH}$ and swelling of wood might also become easier as the material softens with humidity (Siau 1995). A jump and a fall were found in moisture increment (Fig. 2a) and adsorption rate (Fig. 2c) as the RH changed from 20 to $30 \%$ and from 80 to $85 \%$, respectively. The jump is due to the increased target RH step (from 5 to $10 \%$ ), and similarly, for the fall it is due to the decreased target RH step from 10 to $5 \%$ and as such it is an artefact of measurement.

During the desorption isotherm process, the moisture content decrement and equilibrium time had a decreasing trend with the decrease in RH (Fig. 2a, b). The moisture desorption rate, however, generally increased with the decreased $\mathrm{RH}$ (Fig. 2c). The jump occurred from RH 80 to $70 \%$ and the fall occurred from RH 20 to $15 \%$ may also be attributed to the change of $\mathrm{RH}$ step (exposure history). The increase in moisture desorption rate may be associated with the increased stiffness as wood becomes drier.

Compared to untreated wood, modification of wood with glutaraldehyde only caused a minor reduction in the moisture increment/decrement and equilibrium time in the low RH range of $0-20 \%$ during the adsorption and desorption run (Fig. 2a, b). However, the moisture adsorption/desorption rate did not change due to the modification (Fig. 2c). Over the higher RH range of 20-95\% in both adsorption and desorption processes, treatment of wood with glutaraldehyde to low WPG had only minor effect on the moisture increment/decrement and equilibrium time. At higher WPG levels, both the moisture increment/decrement and equilibrium time of wood were apparently reduced by modification compared with untreated control. The moisture adsorption/desorption rates were also found to be reduced to some extent over this RH range. It is worthy of note that in the $\mathrm{RH}$ range of 70-20\%, the moisture decrement of wood treated to high WPG did not present a decreasing tendency with the 
reduction in $\mathrm{RH}$ as did the wood untreated and treated to low WPG. This reduction in moisture change (finally resulting in a low EMC of treated wood) due to modification may be explained by the physical and chemical interactions between glutaraldehyde and cell walls. As it has been well known, two aldehyde groups in the glutaraldehyde molecular chain may in principle react with four hydroxyl groups of wood thereby deactivating these water sorption sites. This will reduce the hydrate water adsorption in the low RH range. At the same time glutaraldehyde can crosslink the microfibrils resultantly restraining the swelling as the treated wood is exposed to humidity. In a moist environment, diffusion of water into the crosslinked cell wall will essentially produce a compressive stress in the cell wall since it cannot swell as does the untreated one. Such a compressive stress can therefore result in the reduction in moisture adsorption (Skaar 1988). Furthermore, incorporation of glutaraldehyde will locate in the nanopores of the cell wall and pre-swell the cell wall. As a result, the size (free space) of nanopores is reduced, and the cell wall swelling due to water adsorption can also be diminished, which results in less accommodation for water (primary dissolved water and condensed water) in the high RH range (Hill 2008).

\section{Isotherm sorption of wood}

In order to compare the effects of treatments on the sorption behaviour of wood, the adsorption and desorption isotherms of wood with different treatments were overlaid based on the measured moisture content (MC) (Fig. 3a, c) and reduced moisture content $\left(\mathrm{MC}_{\mathrm{R}}\right)$ (Fig. 3b, d), respectively. The adsorptive curves of untreated and treated wood displayed a typical sigmoidal shape (Fig. 3a, b) as were found in cellulose-based materials (Skaar 1988; Chatterjee et al. 1997). With the stepwise increase in $\mathrm{RH}$, the moisture content of untreated wood increased (Fig. 3a) due to the abundant hydroxyl groups and elastic swelling of cell walls by water. Treatment of wood to low WPG $(0.5 \%)$ slightly reduced the MC in the high RH range of adsorption and desorption isotherms (Fig. 3a, c). Further increase in the WPG of modified wood caused an apparent reduction in EMC through both the adsorption (Fig. 3a) and desorption (Fig. 3c) run; the sigmoidal curves of desorption isotherms became linear (Fig. 3c). This may be explained by the increased cell wall stiffness due to the microfibril crosslinking by glutaraldehyde. This is also reflected by the constant moisture decrement in the $\mathrm{RH}$ range of $70-20 \%$ (Fig. 2a). The isotherm curves derived from reduced moisture contents $\left(\mathrm{MC}_{\mathrm{R}}\right)$ of modified wood (Fig. 3b, d) had similar tendency in the sorption run as the curves derived from measured moisture content (MC) (Fig. 3a, c). The only difference is that the reduced moisture content values of treated wood were slightly higher than the measured moisture content values.

\section{Sorption hysteresis of wood}

With the same exposure history, modification of wood with glutaraldehyde also reduced the sorption hysteresis compared to untreated wood (Fig. 4a, b). Wood treated to low WPG of $0.5 \%$ only displayed slightly less hysteresis at the RH of 85 and $90 \%$ compared to the untreated wood (Fig. 4). At the higher WPG levels, the 


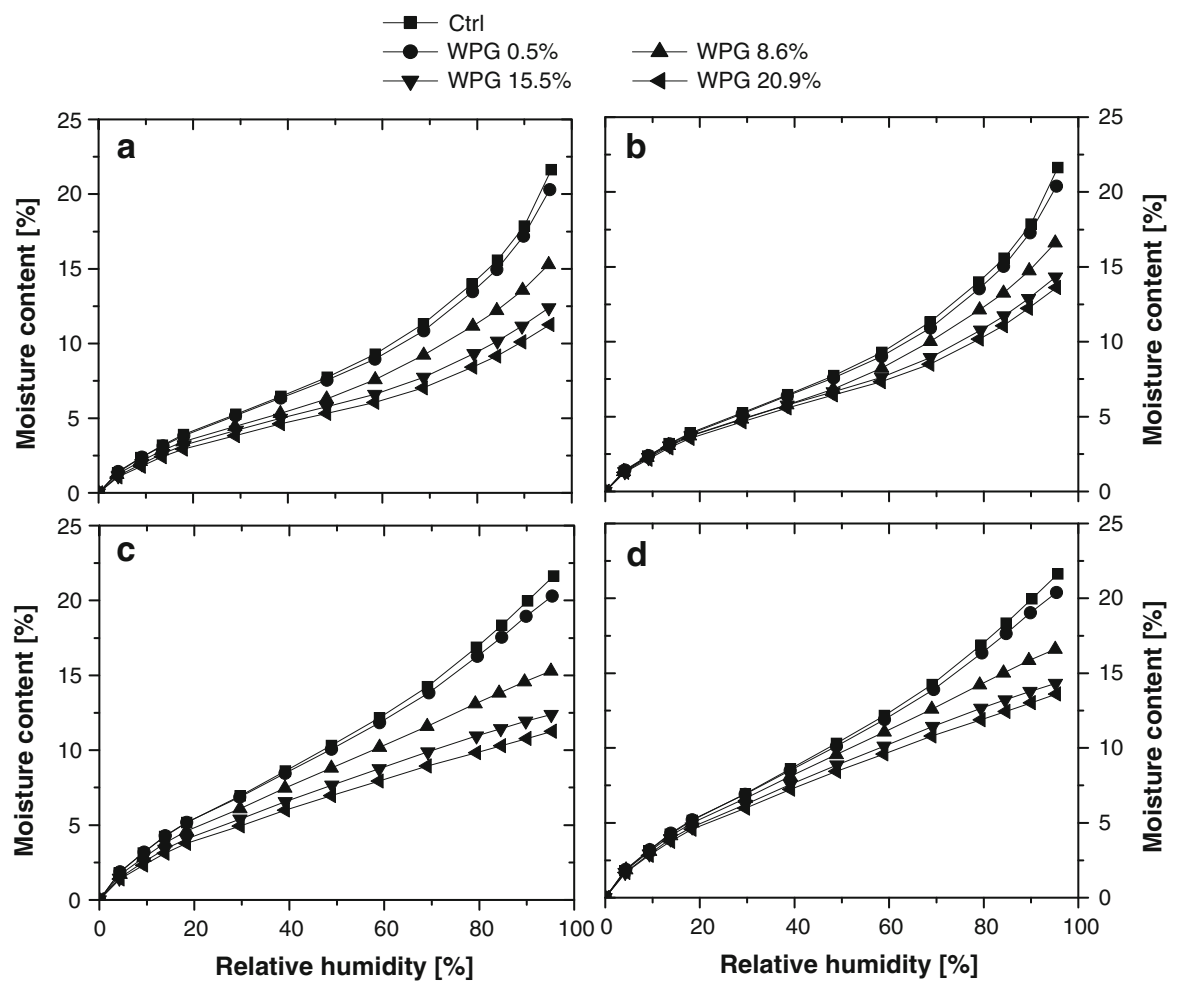

Fig. 3 Moisture adsorption (a, b) and desorption (c, d) behaviour of wood. The moisture contents in a and $\mathbf{c}$ are measured moisture content $(\mathrm{MC})$ and in $\mathbf{b}$ and $\mathbf{d}$ are reduced moisture content $\left(\mathrm{MC}_{\mathrm{R}}\right)$

sorption hysteresis of treated wood was reduced over the full hygroscopic range, especially in the high $\mathrm{RH}$ range, and the maximum hysteresis point shifted from $70 \% \mathrm{RH}$ of untreated wood to $60 \% \mathrm{RH}$ for the modified wood (Fig. 4). The hysteresis calculated from $\mathrm{MC}_{\mathrm{R}}$ of the modified samples also displayed a reduction with the increase in WPG (Fig. 4b); however, such a reduction in hysteresis was relatively lower when compared to the hysteresis calculated from MC (Fig. 4a). It was evidenced from Fig. 5 that compared to the untreated wood, the loop area of the isotherm sorption curve of modified wood decreased with the increase in WPG up to $30 \%$ (derived from $\mathrm{MC}_{\mathrm{R}}$ ) and $40 \%$ (derived from $\mathrm{MC}$ ), respectively. This further confirms the observation of a decrease in sorption hysteresis due to glutaraldehyde treatment (Fig. 4).

The hysteresis ratio of modified wood to untreated control decreased with the increase in WPG during the sorption isotherm (Fig. 6). At low WPG level of $0.5 \%$, the hysteresis ratio curve also showed a sigmoidal shape; however, at the WPG levels higher than $15.5 \%$, the ratio remained constant in the $\mathrm{RH}$ range of $0-70 \%$ and then rapidly decreased in the range of $70-95 \%$. This is consistent with the previous observations that effects of modification mainly occur in the high $\mathrm{RH}$ range (Figs. 2a, 3). The sorption hysteresis does not mean that at a same given RH, the moisture decrement of sample is always lower than its moisture increment 

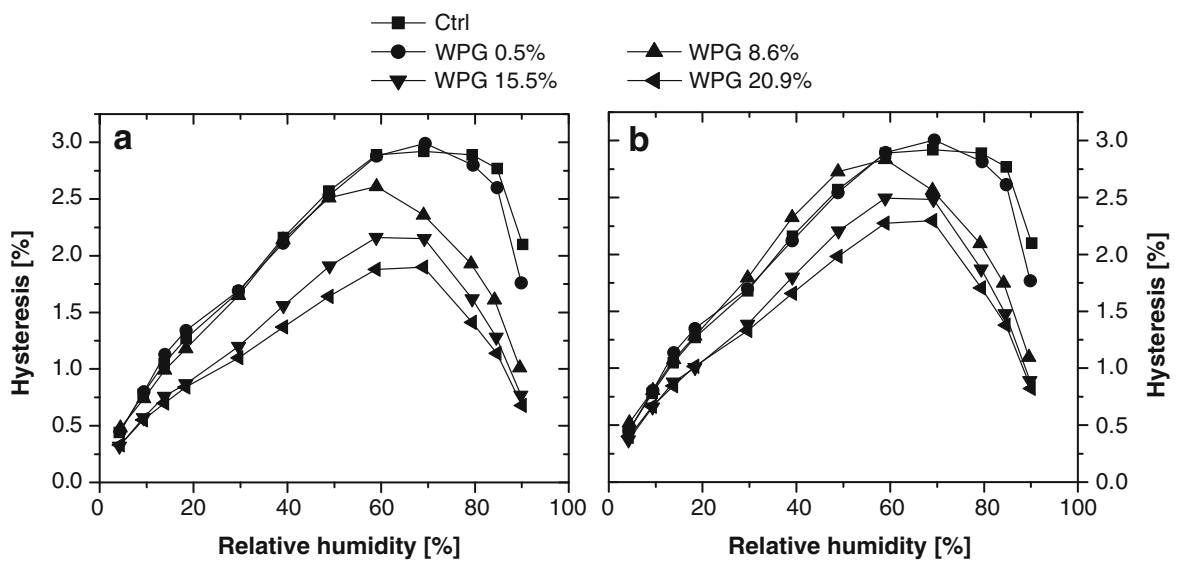

Fig. 4 Hysteresis of untreated and modified wood during the sorption process (obtained by subtraction of equilibrium moisture contents between desorption and adsorption at the same RH level). a Calculated from measured moisture content $(\mathrm{MC})$; $\mathbf{b}$ calculated from reduced moisture content $\left(\mathrm{MC}_{\mathrm{R}}\right)$

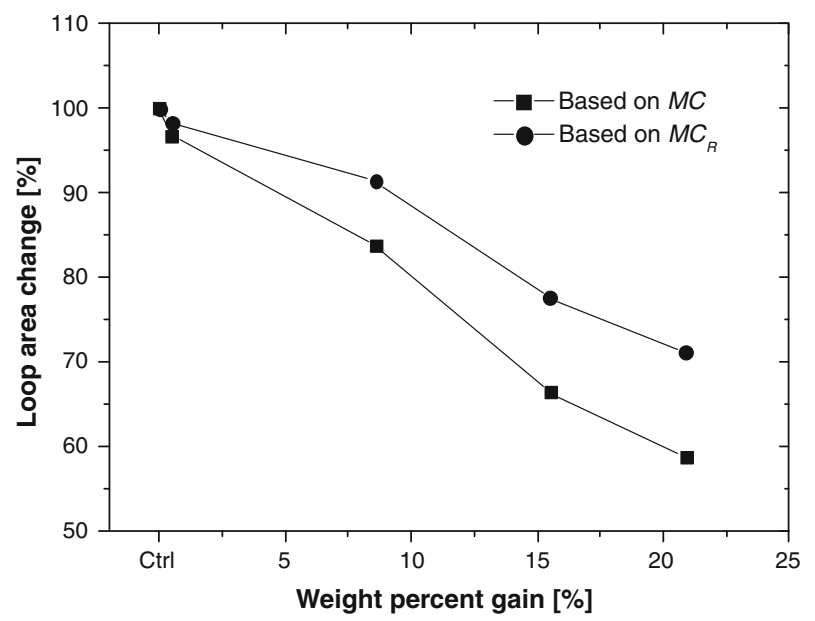

Fig. 5 Change of isotherm loop area of wood modified to different weight per cent gain (on the basis of area of untreated wood) during the sorption process (The area was obtained by integrating the fitting curves of isotherm sorption data by four order polynomial fit, the $\left.R^{2}>0.996\right)$. a Calculated from measured moisture content $(\mathrm{MC})$; $\mathbf{b}$ calculated from reduced moisture content $\left(\mathrm{MC}_{\mathrm{R}}\right)$

previously attained. A comparison of moisture increment and decrement at the same $\mathrm{RH}$ level through the sorption isotherm showed that in the $\mathrm{RH}$ range of 5-70\%, the adsorption moisture increment was always lower than the desorption decrement (Fig. 7a-d). Over the RH of $70 \%$, the increment was generally higher than the decrement at same given RH level, especially at the highest RH level of $95 \%$. Modification of wood with glutaraldehyde distinctly reduced the difference between moisture increment and decrement (Fig. 7b-d) compared to that of untreated wood (Fig. 7a) in the isotherm run. 


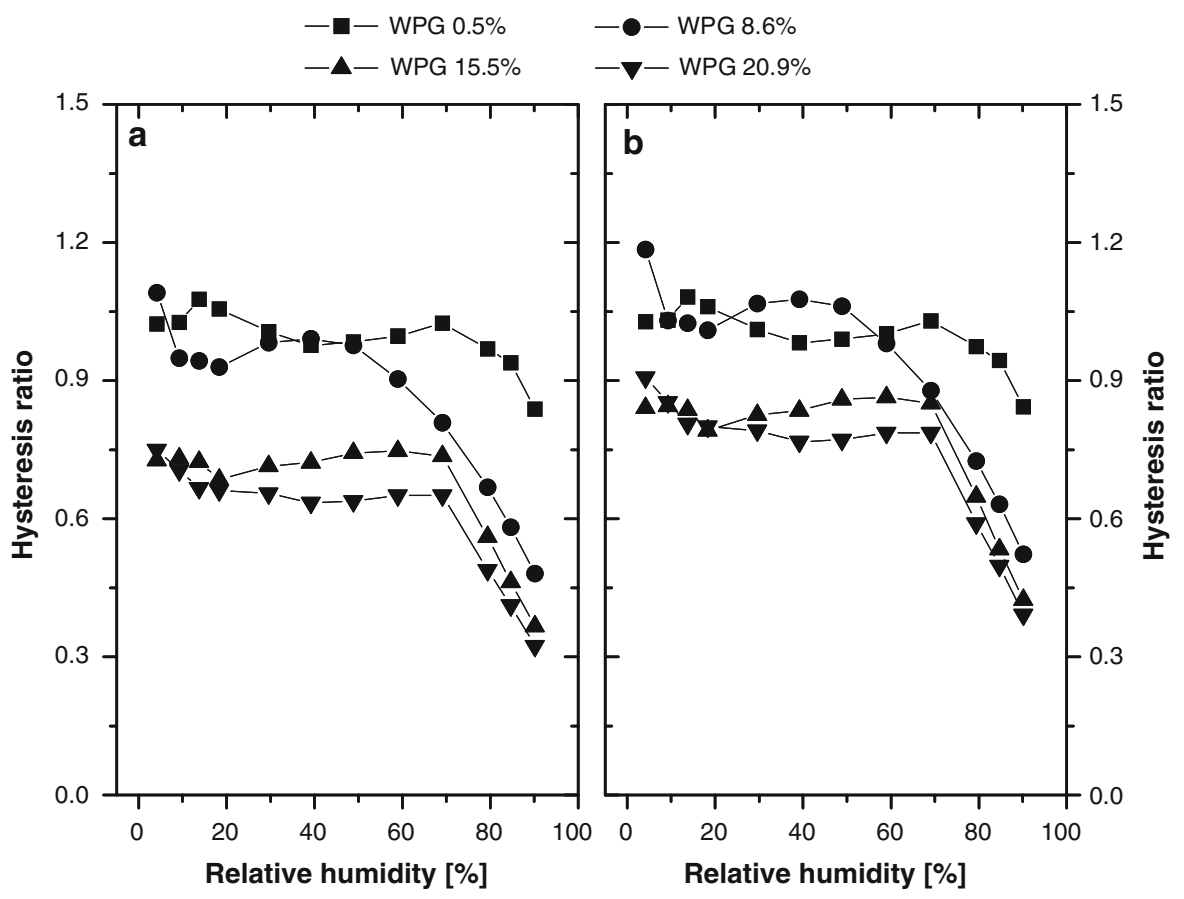

Fig. 6 Hysteresis ratio of modified wood to untreated control at given RH level during the sorption process. a Calculated from measured moisture content (MC); b calculated from reduced moisture content $\left(\mathrm{MC}_{\mathrm{R}}\right)$

The reduction in hysteresis of wood may be explained by the change of cell wall structure due to the chemical modification. The hysteresis effect has previously been interpreted on the basis of sorption phenomena on a glassy solid below the glass transition temperature (Hill et al. 2009a). At the adsorptive stage, the process of water molecules adsorbing onto the sorption sites of cell walls is an exothermic process. The thermal motion of incoming water molecules thus causes the expansion of cell wall nanopores thereby creating new internal surface. During desorption, relaxation of the cell wall matrices to the state they were in during adsorption is kinetically hindered (Lu and Pignatello 2002). Modification with glutaraldehyde results in crosslinking and bulking of the cell walls due to the incorporation of chemicals (Yasuda and Minato 1994; Xiao et al. 2009). Crosslinking reduces the degree of freedom of cell wall polymers and the bulking pre-swells the cell wall. Both effects thus cause an increase in wood stiffness after treatment, which results in less deformation during the sorption process.

\section{Conclusion}

Modification of Scots pine sapwood with glutaraldehyde to different WPGs caused a reduction in the EMC and equilibrium time at different $\mathrm{RH}$ levels. The moisture 


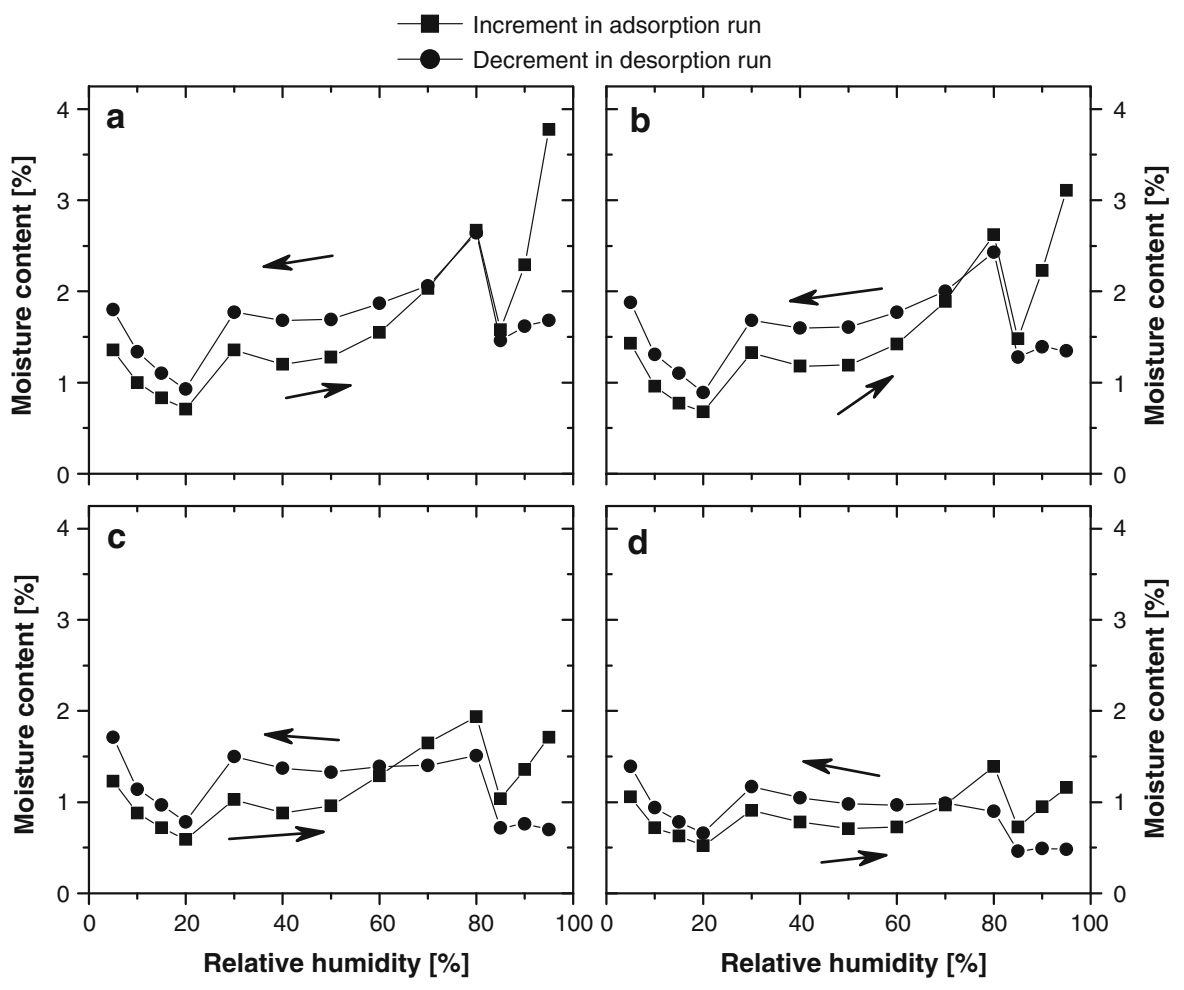

Fig. 7 Moisture increment in the adsorption run (arrow direction, $\mathrm{RH}$ from 5 to 95\%) or moisture decrement in the desorption run (arrow direction, $\mathrm{RH}$ from 95 to 5\%) of untreated and treated wood at each RH level. a Untreated control, $\mathbf{b}$ treated to WPG $0.5 \%$, $\mathbf{c}$ treated to WPG of $8.6 \%$, $\mathbf{d}$ treated to WPG of $20.9 \%$. The moisture content is derived from the modified wood (MC)

adsorption and desorption rate of wood were generally higher in the low relative humidity range than in the high range. Modification primarily reduced the adsorption and desorption rate in high relative humidity range of 20-95\%. The sorption hysteresis exhibited between adsorption and desorption isotherms was reduced by glutaraldehyde modification, and this was more pronounced in the high relative humidity due to the reduction in the difference between adsorption moisture increment and desorption moisture decrement at the same relative humidity level. The desorption isotherm curve became more linear with increasing levels of modification.

The modifying effects of glutaraldehyde on the sorption behaviour of wood may primarily be attributed to three aspects: (1) Reaction of aldehyde group with the hydroxyl groups of cell wall deactivates the sorption sites; (2) Crosslinking of cell wall microfibrils by glutaraldehyde reduces the elasticity of cell wall material and makes the cell wall stiffer; (3) Bulking due to incorporation of glutaraldehyde into cell wall pre-swells the cell wall and reduces the free space of nanopores in the cell 
wall. Further analysis with feasible models for the dynamic sorption behaviour is underway to clarify the modifying effects with glutaraldehyde on the kinetic sorption characteristics.

Acknowledgments The author Zefang Xiao would like to thank the German Academic Exchange Service (DAAD) for the financial support.

\section{References}

Chang HT, Chang ST (2002) Moisture excluding efficiency and dimensional stability of wood improved by acetylation. Bioresour Technol 85:201-204

Chatterjee SG, Ramarao BV, Tien C (1997) Water-vapor sorption equilibria of a bleached-Kraft paperboard-a study of the hysteresis region. J Pulp Paper Sci 23:366-373

Epmeier H, Johansson M, Kliger R, Westin M (2007) Materials properties and their interrelation in chemically modified clear wood of Scots pine. Holzforschung 61:34-42

Hernández RE (2007) Moisture sorption properties of hardwoods as affected by their extraneous substances, wood density, and interlocked grain. Wood Fiber Sci 39:132-145

Hill CAS (2006) Wood modification-chemical thermal and other processes. John Wiley \& Sons, Chichester

Hill CAS (2008) The reduction in the fibre saturation point of wood due to chemical modification using anhydride reagents: a reappraisal. Holzforschung 62:423-428

Hill CAS, Norton A, Newman G (2009a) The water vapor sorption behavior of natural fibers. J Appl Polym Sci 112:1524-1537

Hill CAS, Norton A, Newman G (2009b) The water vapour sorption properties of Sitka spruce determined using a dynamic vapour sorption apparatus. Wood Sci Technol. doi:10.1007/s00226010-0305-y

Hoadley RB (1980) Understanding wood. A craftsman's guild to wood technology, Taunton Press

Jakiela S, Bratasz L, Kozlowski R (2008) Numerical modeling of moisture movement and related stress field in lime wood subjected to changing climate conditions. Wood Sci Technol 42:21-37

Leisen J, Beckham HW, Benham M (2002) Sorption isotherm measurements by NMR. Solid State Nucl Magn Reson 22:409-422

Lu Y, Pignatello J (2002) Demonstration of the "conditioning effect" in soil organic matter in support of a pore deformation mechanism for sorption hysteresis. J Environ Sci Technol 36:4553-4561

Neimsuwan T, Wang S, Taylor AM, Rials TG (2008) Statics and kinetics of water vapor sorption of small loblolly pine samples. Wood Sci Technol 42:493-506

Papadopoulos AN (2005) Moisture adsorption isotherms of two esterified Greek hardwoods. Holz Roh Werkst 63:123-128

Papadopoulos AN, Hill CAS (2003) The sorption of water vapour by anhydride modified softwood. Wood Sci Technol 37:221-231

Siau JF (1995) Wood: influence of moisture on physical properties. Department of Wood Science and Forest Products, Virginia Polytechnic Institute and State University

Skaar C (1988) Wood-water relations. Springer, Berlin

Spalt HA (1958) The fundamentals of water vapor sorption by wood. Forest Prod J 8:288-295

Topgaard D, Södermann O (2001) Diffusion of water absorbed in cellulose fibers studied with ${ }^{1} \mathrm{H}$-NMR. Langmuir 17:2694-2702

Xiao Z, Xie Y, Militz H, Mai C (2009) Modification of wood with glutaraldehyde. In: Proceedings of the 4th European conference on wood modification, Stockholm, Sweden

Xiao Z, Xie Y, Militz H, Mai C (2010) Effect of glutaraldehyde on water related properties of solid wood. Holzforschung (in press)

Yasuda R, Minato K (1994) Chemical modification of wood by non-formaldehyde cross-linking reagents. Part I. Improvement of dimensional stability and acoustic properties. Wood Sci Technol 28:101-110

Yasuda R, Minato K, Norimoto M (1994) Chemical modification of wood by nonformaldehyde crosslinking reagents. Part 2. Moisture adsorption and creep properties. Wood Sci Technol 28:209-218 